\title{
Selection of Material Handling Equipment using the AHP and MOORA
}

\author{
Sule I Satoglu *, İbrahim Türkekul \\ Department of Industrial Engineering, Mechanical Faculty, Yildiz Technical University, Turkey \\ Address: Yıldız, 34349 Beşiktaş/İstanbul, Turkey \\ *Corresponding author: s.isatoglu@gmail.com
}

\section{ARTICLE INFO}

\section{Article history}

Received October 12, 2020

Revised February 25, 2021

Accepted February 27, 2021

Available Online February 28, 2021

Keywords

AHP

MOORA

MCDM

Selection Material Handling

\begin{abstract}
Choosing the best Material Handling Equipment (MHE) is an aspect that needs to be considered in the industrial sector because the amount of capital involved in the procurement process is very large. Many substantial factors influence the MHE selection process. One popular approach was chosen to resolve the MHE selection issue. The concept of Multi-Criteria Decision Making (MCDM) is popularly used because it can solve and handle conflicting components in the MHE selection process. This study proposes the Analytical Hierarchy Process (AHP) and MultiObjective Optimization on the Basis of Ratio Analysis (MOORA) procedures in MHE selection. AHP is proposed to weigh the MHE selection criteria. MOORA is proposed to compute the rankings of the MHE alternatives. Case studies are applied to this problem. The results show that the cost criterion gives the greatest weight in selecting MHE. Other than that, Of the five selected MHE alternatives, Hand Pallet Truck is the MHE that has the best rating.
\end{abstract}

This is an open-access article under the CC - BY-SA license.

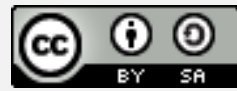

\section{Introduction}

Raw materials and finished products are objects that are always needed in work facilities [1]. The flow of raw materials is an important aspect that needs attention because it impacts the production process [2] [3]. Generally, moving raw materials and finished products is an activity of transportation from one place to another that uses human labor or equipment [4] [5]. Therefore, it is essential to pay attention to moving materials to avoid losing products, maintaining time consumption, and maintaining finance [6]. Material Handling Equipment (MHE) selection is critical to research by paying attention to these factors. The proper MHE selection can increase productivity and cost savings by $25-87 \%$ [7]. Recently, a topic on the selection of MHE is interesting among researchers.

Researchers have extensively investigated the problem of MHE selection. Various approaches are used to solve problems related to MHE selection. In general, this approach can be divided into four, namely Multi-Criteria Decision Making (MCDM), Artificial Intelligence (AI), Optimization, and Hybrid. Tuzkaya, et al. [8] proposed a Fuzzy Integration - Analytical Network Process and Preference Ranking Organization Method. Gaur and Ronge [9], Braglia, et al. [10], and Varun, et al. [11] use the Analytical Hierarchy 
Process (AHP) method to obtain the best MHE weight. Furthermore, Verma, et al. [2] integrate the AHP-Technique for Order Preference by Similarity to Ideal Solution (Topsis) method for a similar problem. In addition, Yogi and Solanki [12] propose the Hybrid Entropy-VIse Kriterijumska Optimizacija I Kompromisno Rasenje and Entropy-Topsis methods. The Fuzzy-Promethee method is proposed by Gul, et al. [13] for the MHE selection process. Furthermore, Fuzzy-Gray is also proposed by Mousavi, et al. [14]. Several other procedures are also proposed in MHE selection, such as simulation procedures [15]. Hybrid Fuzzy and Genetic Algorithm [16]. Hybrid Fuzzy [17]. Weighted Utility Additive [18]. Fuzzy Multi-Attribute [19] and the Genetic Algorithm approaches are proposed by Haidar and Naoum [20].

Based on previous research, it is rare to find MHE studies that consider the benefits and cost criteria in MHE selection. Benefit and cost criteria types can be used as alternatives in supplier selection. These types of criteria can be compared to produce MHE selection solutions. To the best of the author's knowledge, research on MHE selection is generally based on suppliers' importance in each criterion. In this study, we propose to use the integration of the AHP and the Multi-Objective Optimization on the Basis of Ratio Analysis (MOORA) methods as alternative solutions for MHE selection. AHP can make broad and abstract problems clear and structured [21]. In addition, AHP can reach all types of attributes, both quantitative and qualitative [22]. AHP is proposed as a weighting procedure for MHE criteria. Furthermore, the selection of the best MHE is based on the MOORA method. MOORA is a straightforward, stable, and robust method that can provide accurate and targeted results [23]. MOORA has been popularly used for supplier selection [24], Stock Investment [25], Composite Material selection [26], and Green Supply Chain Management problems [27]. The MOORA method also supports a wide measurement scale, taking into account the types of benefit or cost criteria. The contribution of this study is to propose a more efficient and effective procedure in MHE selection using the AHP and MOORA methods. In this study, AHP was chosen as the weighting method, while MOORA was used to determine the best ranking. The author tried to integrate AHP and MOORA methods to solve the Material Handling Equipment selection problems in the manufacturing industry.

This paper's structure is presented as follows: suggestion methods and data collection are presented in section 2 , results and discussion in section 3 , and conclusions are presented in section 4 .

\section{Methods}

\subsection{AHP-MOORA Integration}

This study proposes the integration of 2 methods, namely AHP and MOORA. Hopefully, these two methods can be used to solve the MHE selection problem. AHP is a popular method for weighting proposed by Saaty [28]. Meanwhile, MOORA is a method used to rank the alternatives proposed by Brauers and Zavadskas [23]. The framework related to AHP-MOORA integration can be seen in Fig. 1.

The first stage carried out within the framework is identifying the criteria used in the selection of MHE. The decision-maker identifies the criteria required in the MHE selection process. Each criterion must be classified as either a benefit or cost. In the second stage, the decision-maker performs pairwise comparisons to criteria. The result of this pairwise comparison is made into the AHP matrix. Pairwise comparison is proposed using a priority scale of 1-9 with the following levels of importance: 1 indicates that both criteria are important; 3 indicates 1 level higher compared to other criteria (sufficient); 5 indicates 
2 levels higher compared to other criteria (good); 7 indicates 3 levels higher compared to other criteria (better); 9 shows four levels higher compared to other criteria (the best). Meanwhile, 2,4,6,8 show Intermediate scale.

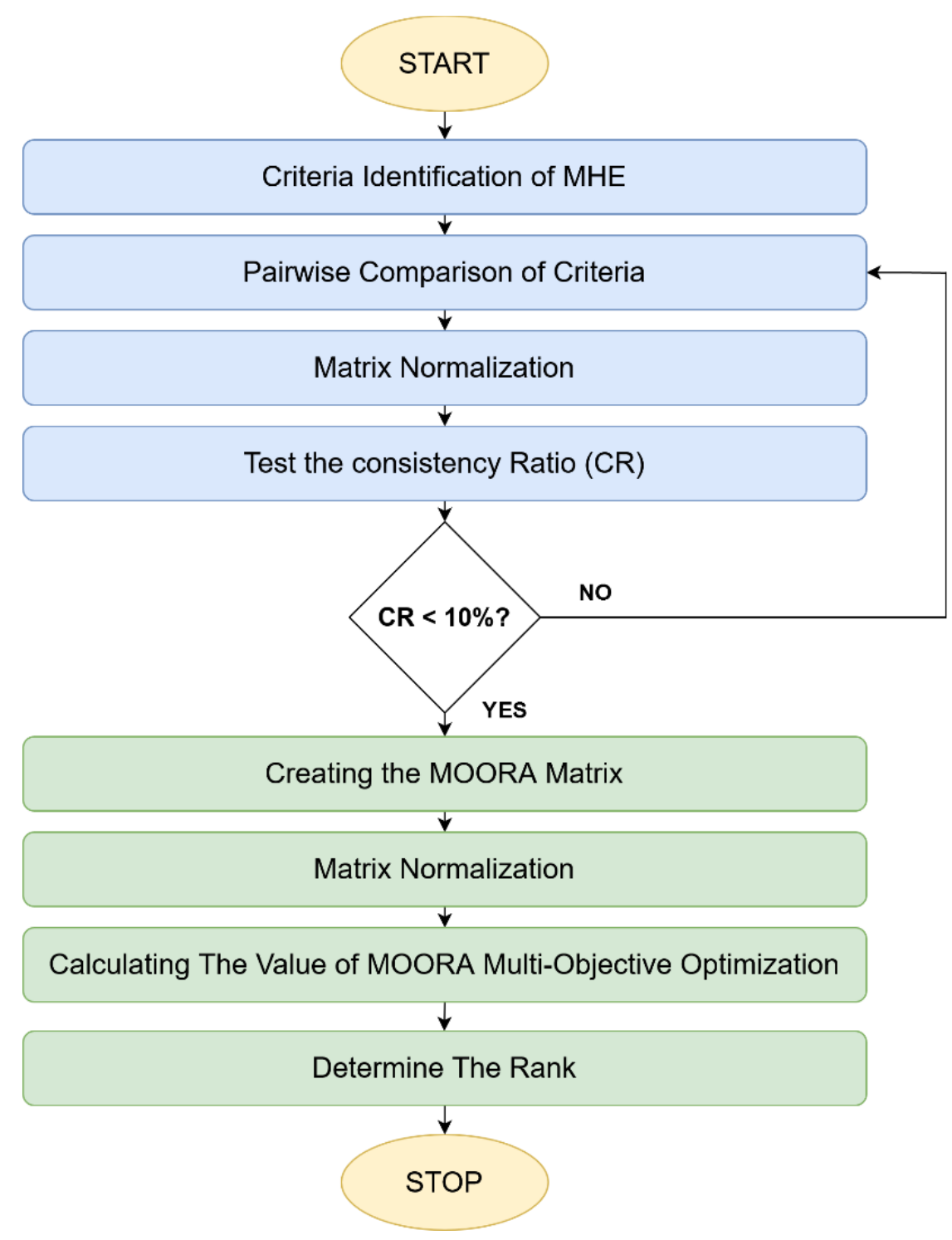

Fig. 1. Framework MHE selection

The third stage is to carry out normalization. This stage is done by dividing the column value by the number of columns in the AHP matrix. The normalization process is carried out to normalize existing data. The fourth stage is the weighting process of the MHE criteria used $\left(W_{i j}\right)$. At this weighting stage, several calculations are also included, such as the calculation of Eigen Vector ( $\lambda$ max), RI (Random Index), CI (Consistency Index), and CR (Consistency Ratio). The required CR value is less than $10 \%$. CR value of more than $10 \%$ indicates inconsistent data and must be repeated in the pairwise comparison process. The calculation of the weight of the criteria, Eigen Vector ( $\lambda$ max $), R I$ (Random Index), CI (Consistency Index), and CR (Consistency Ratio) can be seen in equations (1)-(4). 


$$
\begin{aligned}
& W_{i j}=\frac{a_{i j}}{n} \\
& \lambda \max =\frac{\sum a_{i j}}{\mathrm{n}} \\
& \mathrm{CI}=\frac{(\lambda \max -n)}{(\mathrm{n}-1)} \\
& \mathrm{CR}=\frac{\mathrm{CI}}{\mathrm{RI}}
\end{aligned}
$$

Where:

Wij $\quad$ : Weighting Value

aij $\quad:$ Normalization matrix in row $i$ column $j$

$n \quad$ : Number of criteria being compared

The fifth stage is to create the MOORA matrix presented in equation (5). This matrix is based on the assessment data of each MHE alternative to the criteria. The assessment uses a Likert scale of 1-5 with the following conditions: Very Poor (1); Poor (2); Fair (3); Good (4); Excellent (5). The sixth step is to normalize the MOORA matrix by dividing the column values by the number of columns. This stage is based on equation (6). The seventh step is to determine the MOORA multi-objective optimization value by multiplying the MOORA matrix by the criteria weights obtained from the AHP procedure. The MOORA rating is based on the difference in the weight of each supplier's benefit and cost criteria. The formula for calculating each supplier's benefit and cost criteria is presented in equation (6). The last step is to determine the ranking for each $\mathrm{MHE}$ alternative. The value of Yi determines the rank. The highest Yi score yields the best ranking.

$$
\begin{aligned}
X & =\left|\begin{array}{ccc}
x_{11} & x_{12} \ldots & x_{1 n} \\
x_{21} & x_{22} & x_{2 n} \\
\vdots & & \vdots \\
x_{m 1} & x_{m 2} & x_{m n}
\end{array}\right| \\
X_{i j}^{*} & =\frac{x_{i j}}{\sqrt{\left[\sum_{j=1}^{m} x_{i j}^{2}\right.}}
\end{aligned}
$$

\footnotetext{
Where:

i $\quad: 1,2, \ldots, \mathrm{g}$ - criteria/attributes with maximized status;

i $\quad: g+1, g+2, \ldots, n-c r i t e r i a / a t t r i b u t e s$ with minimized status;

Wij : Weight of the AHP calculation

Yi : Difference in the weight of the benefit and cost criteria for each supplier

xij $\quad$ : Alternative Matrix $j$ on $i$ criterion

$i \quad: 1,2,3,4, \ldots, \mathrm{n}$ is the sequence number of attributes or criteria

$j \quad: 1,2,3,4, \ldots, \mathrm{m}$ is the alternate sequence number

$X * i j \quad$ : Alternative normalization matrix $j$ on $i$ criterion

$m \quad$ : Number of alternatives
} 


\subsection{Data Collection}

This research was conducted at a manufacturing company in Turkey. Five types of Material Handling Equipment were chosen for the selection process. The decision-makers of this study were 3 . The decision-maker conducted a focus group discussion to determine criteria, a pairwise comparison rating of the criteria, and a rating of the selected $\mathrm{MHE}$ alternatives.

The criteria selected in the selection of MHE are presented in Table 1. The criteria selected are also based on previous research. The focus group discussion of the pairwise comparison for each criterion can be seen in Table 2 further. The results of the MHE alternative rating for each criterion are presented in Table 3.

Table 1. Criteria used

\begin{tabular}{lcc} 
Criteria & Code & Criteria Type \\
\hline Ease to operate [29] & ETO & Benefit \\
\hline Application [30] & AP & Benefit \\
\hline Load-carrying capacity [31] & LCC & Benefit \\
\hline Power required [2] & PR & Cost \\
\hline Flexibility in material [32] & FIM & Benefit \\
\hline Cost [33] & C & Cost \\
\hline Availability of spare parts [34] & AV & Benefit \\
\hline On-site repair [35] & OSR & Benefit \\
\hline Area constraints [36] & AC & Benefit \\
\hline Risk [37] & R & Cost \\
\hline Distance to be moved [38] & DIS & Benefit \\
\hline
\end{tabular}

Table 2. Pairwise comparison between criteria

\begin{tabular}{cccccccccccc}
\hline Criteria & C & ETO & R & AP & LCC & PR & FIM & AV & OSR & AC & DIS \\
\hline C & 1 & 2 & 2 & 5 & 5 & 5 & 5 & 6 & 7 & 7 & 7 \\
\hline ETO & $1 / 2$ & 1 & 3 & 3 & 3 & 4 & 5 & 5 & 5 & 5 & 5 \\
\hline $\mathrm{R}$ & $1 / 2$ & $1 / 3$ & 1 & 2 & 3 & 3 & 4 & 4 & 4 & 4 & 4 \\
\hline $\mathrm{AP}$ & $1 / 5$ & $1 / 3$ & $1 / 2$ & 1 & 2 & 3 & 3 & 3 & 3 & 3 & 3 \\
\hline $\mathrm{LCC}$ & $1 / 5$ & $1 / 3$ & $1 / 3$ & $1 / 2$ & 1 & 3 & 3 & 3 & 3 & 3 & 3 \\
\hline $\mathrm{PR}$ & $1 / 5$ & $1 / 4$ & $1 / 3$ & $1 / 3$ & $1 / 3$ & 1 & 2 & 2 & 2 & 2 & 3 \\
\hline $\mathrm{FIM}$ & $1 / 5$ & $1 / 5$ & $1 / 4$ & $1 / 3$ & $1 / 3$ & $1 / 2$ & 1 & 1 & 2 & 1 & 2 \\
\hline $\mathrm{AV}$ & $1 / 6$ & $1 / 5$ & $1 / 4$ & $1 / 3$ & $1 / 3$ & $1 / 2$ & $1 / 1$ & 1 & 1 & 1 & 1 \\
\hline $\mathrm{OSR}$ & $1 / 7$ & $1 / 5$ & $1 / 4$ & $1 / 3$ & $1 / 3$ & $1 / 2$ & $1 / 2$ & $1 / 1$ & 1 & 2 & 2 \\
\hline $\mathrm{AC}$ & $1 / 7$ & $1 / 5$ & $1 / 4$ & $1 / 3$ & $1 / 3$ & $1 / 2$ & $1 / 1$ & $1 / 1$ & $1 / 2$ & 1 & 2 \\
\hline $\mathrm{DIS}$ & $1 / 7$ & $1 / 5$ & $1 / 4$ & $1 / 3$ & $1 / 3$ & $1 / 3$ & $1 / 2$ & $1 / 1$ & $1 / 2$ & $1 / 2$ & 1 \\
\hline
\end{tabular}


Table 3. MHE rating in each criterion

\begin{tabular}{|c|c|c|c|c|c|c|c|c|c|c|c|}
\hline MHE alternative & ETO & $\mathrm{AP}$ & $\mathrm{LCC}$ & PR & FIM & $\mathrm{C}$ & $\mathrm{AV}$ & OSR & $\mathrm{AC}$ & $\mathrm{R}$ & DIS \\
\hline $\begin{array}{l}\text { Hand Pallet } \\
\text { Truck }\end{array}$ & 4 & 3 & 4 & 5 & 5 & 5 & 5 & 3 & 5 & 5 & 5 \\
\hline $\begin{array}{l}\text { Hydraulic Hand } \\
\text { Pallet Truck }\end{array}$ & 2 & 3 & 3 & 3 & 3 & 3 & 3 & 3 & 3 & 3 & 3 \\
\hline $\begin{array}{l}\text { Hydraulic Pallet } \\
\text { Truck }\end{array}$ & 2 & 3 & 4 & 3 & 4 & 3 & 3 & 3 & 3 & 3 & 4 \\
\hline $\begin{array}{l}\text { Electric Pallet } \\
\text { Truck }\end{array}$ & 2 & 3 & 3 & 4 & 3 & 3 & 3 & 5 & 3 & 3 & 4 \\
\hline $\begin{array}{l}\text { Semi Electric Pallet } \\
\text { Truck }\end{array}$ & 2 & 4 & 3 & 3 & 3 & 3 & 3 & 3 & 3 & 3 & 3 \\
\hline
\end{tabular}

\section{Results and Discussion}

\subsection{Weighting of the MHE Criteria}

The results of the weighting of the criteria can be seen in Fig. 2. Based on the calculation of the AHP method, the results show that the Cost (C) criterion has the highest weight, followed by the Ease To Operate (ETO) and Risk (R) criteria. The company makes the price (Cost) a priority because the equipment maintenance procedure requires much money. In addition, the ease of use and the risk of each tool is also a reference in the process of Material Handling Equipment selection. This study supports the research conducted by Verma, et al. [2], Momani and Ahmed [39], and Kumar and Raj [40]. Distance to be moved is a criterion that has received little attention. It is an indication that the company does not consider the distance of the material to be moved. It is reinforced by the low value of the Area constraints criterion. The result of criteria weighting is used to determine the rank of material handling equipment using the MOORA method presented in the following sub-section.

\subsection{The Determination of MHE Rank}

The alternative ranking is done using the MOORA method. The results of normalization of the MHE rating matrix for each criterion are presented in Table 4.

Table 4. MOORA Normalization Matrix Value

\begin{tabular}{|c|c|c|c|c|c|c|c|c|c|c|c|}
\hline & ETO & AP & LCC & PR & FIM & C & $\mathrm{AV}$ & OSR & $\mathrm{AC}$ & $\mathrm{R}$ & DIS \\
\hline $\begin{array}{l}\text { Hand Pallet } \\
\text { Truck }\end{array}$ & 0.71 & 0.42 & 0.52 & 0.61 & 0.61 & 0.64 & 0.64 & 0.38 & 0.64 & 0.38 & 0.58 \\
\hline $\begin{array}{l}\text { Hydraulic Hand } \\
\text { Pallet Truck }\end{array}$ & 0.35 & 0.42 & 0.39 & 0.36 & 0.36 & 0.38 & 0.38 & 0.38 & 0.38 & 0.38 & 0.35 \\
\hline $\begin{array}{l}\text { Hydraulic Pallet } \\
\text { Truck }\end{array}$ & 0.35 & 0.42 & 0.52 & 0.36 & 0.49 & 0.38 & 0.38 & 0.38 & 0.38 & 0.38 & 0.46 \\
\hline $\begin{array}{l}\text { Electric Pallet } \\
\text { Truck }\end{array}$ & 0.35 & 0.42 & 0.39 & 0.49 & 0.36 & 0.38 & 0.38 & 0.64 & 0.38 & 0.64 & 0.46 \\
\hline $\begin{array}{l}\text { Semi Electric Pallet } \\
\text { Truck }\end{array}$ & 0.35 & 0.55 & 0.39 & 0.36 & 0.36 & 0.38 & 0.38 & 0.38 & 0.38 & 0.38 & 0.35 \\
\hline
\end{tabular}




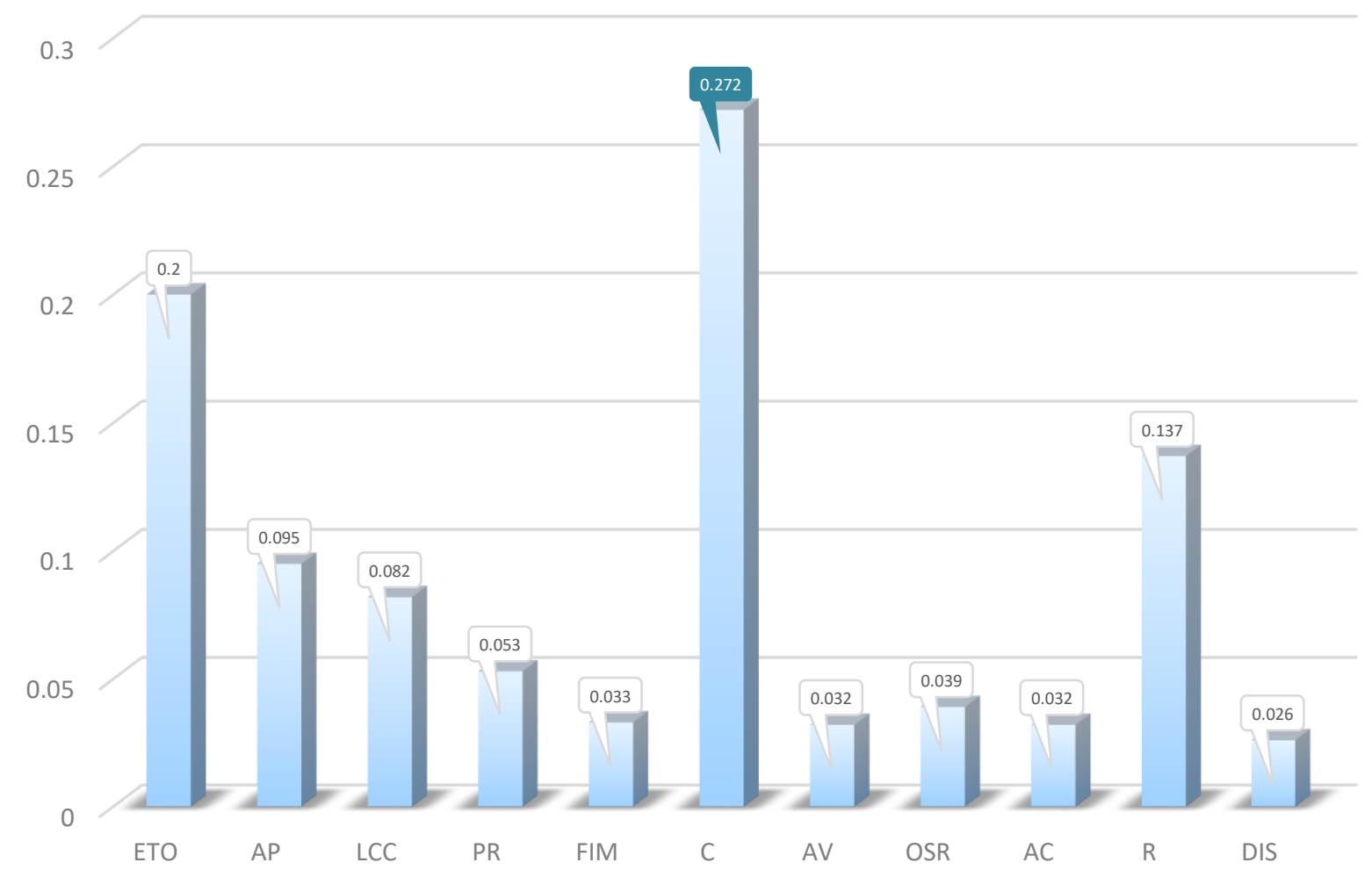

Fig. 2. The results of criteria weighting using AHP

The Normalization Matrix Value is used to determine the MOORA Multi-Objective Optimization Value. The results of the MOORA Multi-Objective Optimization value are illustrated in Table 5. At this stage, the type of criteria has an impact on MHE selection. Criteria with the "benefit" type are marked with MAX. Furthermore, the criteria with the "Cost" type are marked with the label MIN. Power Required, Cost, and Risk criteria are considered to harm MHE selection. Meanwhile, other criteria are considered to have a beneficial impact on MHE selection. The results of the rating of the multi-objective MOORA optimization are presented in Table 5.

Based on the multi-objective scores in Table 5, the MHE ratings for each alternative are presented. The rating of the difference in the weight of each supplier's benefit and cost criteria for each alternative can be seen in Fig. 3. These results indicate that the highest Yi score is obtained by Hand Pallet Truck with a value of 0.06 . It is followed by Hydraulic Pallet Truck and Semi-Electric Pallet Truck with the same value, 0.04. Then, the fourth rank is occupied by Hydraulic Hand Pallet Truck with a value of 0.03. The fifth position is occupied by the Electric Pallet Truck with a value of 0.00 . The MHE rank in more detail can be seen in Table 6. 
Table 5. Multi-Objective MOORA Optimization Score

\begin{tabular}{|c|c|c|c|c|c|c|c|c|c|c|c|}
\hline MHE & ETO & $\mathrm{AP}$ & $\mathrm{LCC}$ & PR & FIM & $\mathrm{C}$ & AV & OSR & $\mathrm{AC}$ & $\mathrm{R}$ & DIS \\
\hline $\begin{array}{l}\text { Hand Pallet } \\
\text { Truck }\end{array}$ & 0.14 & 0.04 & 0.04 & 0.03 & 0.02 & 0.17 & 0.02 & 0.01 & 0.02 & 0.05 & 0.02 \\
\hline $\begin{array}{l}\text { Hydraulic Hand } \\
\text { Pallet Truck }\end{array}$ & 0.07 & 0.04 & 0.03 & 0.02 & 0.01 & 0.10 & 0.01 & 0.01 & 0.01 & 0.05 & 0.01 \\
\hline $\begin{array}{l}\text { Hydraulic Pallet } \\
\text { Truck }\end{array}$ & 0.07 & 0.04 & 0.04 & 0.02 & 0.02 & 0.10 & 0.01 & 0.01 & 0.01 & 0.05 & 0.01 \\
\hline $\begin{array}{l}\text { Electric Pallet } \\
\text { Truck }\end{array}$ & 0.07 & 0.04 & 0.03 & 0.03 & 0.01 & 0.10 & 0.01 & 0.02 & 0.01 & 0.09 & 0.01 \\
\hline $\begin{array}{l}\text { Semi Electric Pallet } \\
\text { Truck }\end{array}$ & 0.07 & 0.05 & 0.03 & 0.02 & 0.01 & 0.10 & 0.01 & 0.01 & 0.01 & 0.05 & 0.01 \\
\hline & MAX & MAX & MAX & MIN & MAX & MIN & MAX & MAX & MAX & MIN & MAX \\
\hline
\end{tabular}

Table 6. Rank of each MHE alternatives

\begin{tabular}{lc} 
Material Handling Equipment & RANK \\
\hline Electric Pallet Truck & 5 \\
\hline Semi Electric Pallet Truck & 3 \\
\hline Hand Pallet Truck & 1 \\
\hline Hydraulic Hand Pallet Truck & 4 \\
Hydraulic Pallet Truck & 2
\end{tabular}

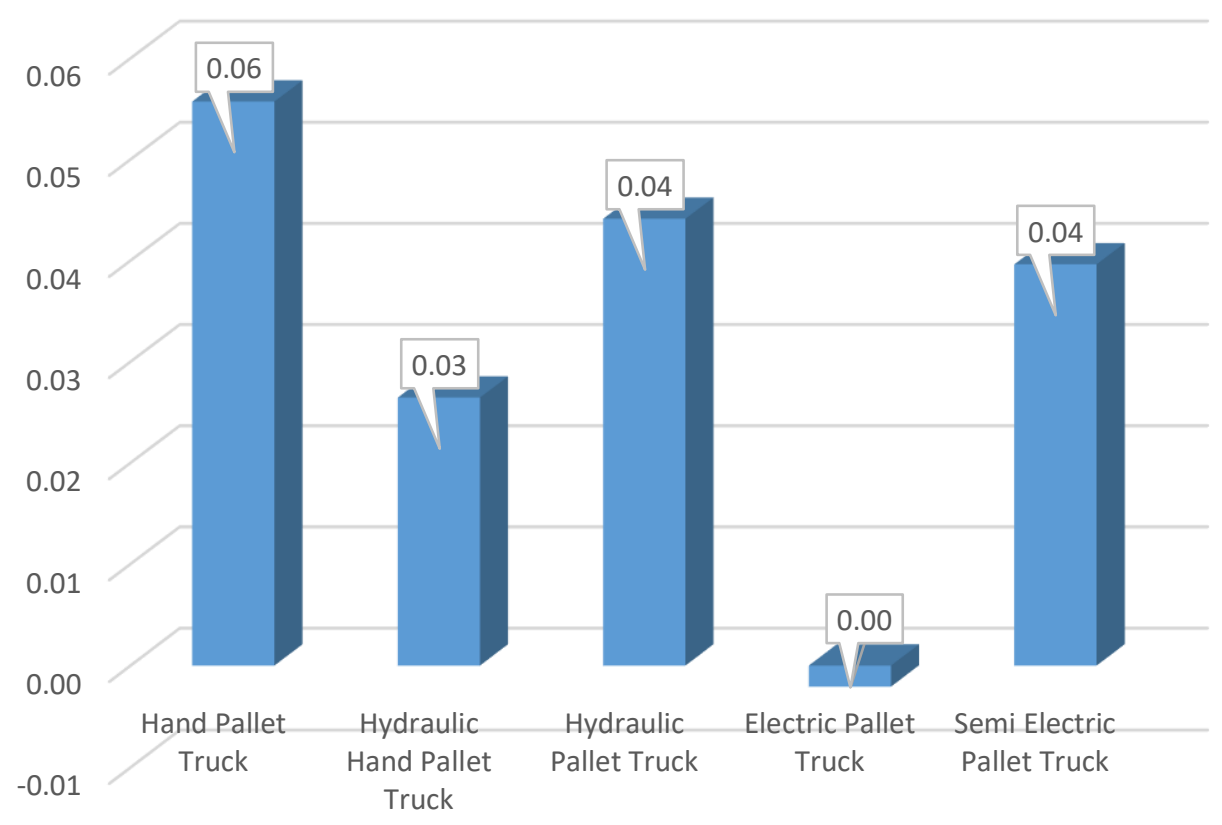

Fig. 3. The Yi score of each alternative obtained from the calculation 


\section{Conclusion}

This study aims to solve the problem of MHE selection using the AHP and MOORA methods. Integration of AHP and MOORA methods was used to assess 11 criteria and 5 MHE alternatives. Based on the AHP method, the results of this study indicate that the Cost (C) criterion is the criterion that has the highest weight. Furthermore, Distance To Be Moved (DIS) has the lowest weight. Based on MOORA, the MHE selected is a Hand Pallet Truck. Furthermore, an MHE that is not recommended is the Electric Pallet Truck. This study has limitations, including information that is considered definite. In further research, it is necessary to develop it by considering the characteristics of fuzzy or indefinite information.

\section{Acknowledgments}

The author would like to send his gratitude to the Mechanical Faculty, Department of Industrial Engineering, Yildiz Technical University for the full support to conduct this study. His next gratitude is delivered to the Industrial Engineering Laboratory-for, allowing its facilities to be used in the research conduct.

\section{References}

[1] F. T. S. Chan, "Design of material handling equipment selection system: an integration of expert system with analytic hierarchy process approach," Integrated Manufacturing Systems, vol. 13, pp. 58-68, 2002. https://doi.org/10.1108/09576060210411512.

[2] P. K. Verma, R. Kumar, and G. S. Goindi, "Evaluation of Material Handling Using MCDM Techniques: A Case Study," in Advances in Production and Industrial Engineering, ed: Springer, 2021, pp. 389-401. https://doi.org/10.1007/978-981-155519-0_30.

[3] O. F. Yilmaz, B. Oztaysi, M. B. Durmusoglu, and S. C. Oner, "Determination Of Material Handling Equipment For Lean In-Plant Logistics Using Fuzzy Analytical Network Process Considering Risk Attitudes Of The Experts," International Journal of Industrial Engineering, vol. 24, 2017.

[4] S. Pattanayak and B. Choudhury, "An effective trajectory planning for a material handling robot using PSO algorithm," in Computational Intelligence in Data Mining, ed: Springer, 2020, pp. 73-81. https://doi.org/10.1007/978-981-13-8676-3_7.

[5] S. Chakraborty and D. Banik, "Design of a material handling equipment selection model using analytic hierarchy process," The International Journal of Advanced Manufacturing Technology, vol. 28, pp. 1237-1245, 2006. https://doi.org/10.1007/s00170-004-2467-y.

[6] E. L. Fisher, J. B. Farber, and M. G. Kay, "Mathes: An expert system for material handling equipment selection," Engineering Costs and Production Economics, vol. 14, pp. 297-310, 1988. https://doi.org/10.1016/0167-188X(88)90034-1.

[7] J. A. Tompkins, J. A. White, Y. A. Bozer, and J. M. A. Tanchoco, Facilities planning: John Wiley \& Sons, 2010.

[8] G. Tuzkaya, B. Gülsün, C. Kahraman, and D. Özgen, "An integrated fuzzy multicriteria decision making methodology for material handling equipment selection problem and an application," Expert Systems with Applications, vol. 37, pp. 2853 2863, 2010. https://doi.org/10.1016/j.eswa.2009.09.004. 
[9] A. Gaur and B. Ronge, "Ranking Material Handling Equipment Selection Criteria by AHP," in Techno-Societal 2018, ed: Springer, 2020, pp. 175-182. https://doi.org/10.1007/978-3-030-16962-6_18.

[10] M. Braglia, R. Gabbrielli, and D. Miconi, "Material handling device selection in cellular manufacturing," Journal of Multi-Criteria Decision Analysis, vol. 10, pp. 303-315, 2001. https://doi.org/10.1002/mcda.310.

[11] S. Varun, R. Harshita, S. Pramod, and D. Nagaraju, "Evaluation and selection of material handling equipment in iron and steel industry using analytic hierarchy process," in IOP Conference Series: Materials Science and Engineering, 2017, p. 012060. https://doi.org/10.1088/1757-899x/197/1/012060.

[12] V. Yogi and S. Solanki, "Selection of Material Handling Equipment using Hybrid Entropy-VIKOR and Entropy-TOPSIS Techniques," Industrial Engineering Journal, vol. 12, pp. 1-12, 2019.

[13] M. Gul, E. Celik, A. T. Gumus, and A. F. Guneri, "A fuzzy logic based PROMETHEE method for material selection problems," Beni-Suef University Journal of Basic and $\begin{array}{llllll}\text { Applied } & \text { Sciences, } & \text { vol. } & 7, & \text { pp. } & 68-79,\end{array}$ https://doi.org/10.1016/j.bjbas.2017.07.002.

[14] S. M. Mousavi, B. Vahdani, R. Tavakkoli-Moghaddam, and N. Tajik, "Soft computing based on a fuzzy grey group compromise solution approach with an application to the selection problem of material handling equipment," International Journal of Computer Integrated Manufacturing, vol. 27, pp. 547-569, 2014. https://doi.org/10.1080/0951192X.2013.834460.

[15] I. Mahdavi, B. Shirazi, and N. Sahebjamnia, "Development of a simulation-based optimisation for controlling operation allocation and material handling equipment selection in FMS," International Journal of Production Research, vol. 49, pp. 69817005, 2011. https://doi.org/10.1080/00207543.2010.534826.

[16] S. H. L. Mirhosseyni and P. Webb, "A Hybrid Fuzzy Knowledge-Based Expert System and Genetic Algorithm for efficient selection and assignment of Material Handling Equipment," Expert Systems with Applications, vol. 36, pp. 11875-11887, 2009. https://doi.org/10.1016/j.eswa.2009.04.014.

[17] A. Hadi-Vencheh and A. Mohamadghasemi, "A new hybrid fuzzy multi-criteria decision making model for solving the material handling equipment selection problem," International Journal of Computer Integrated Manufacturing, vol. 28, pp. 534-550, 2015. https://doi.org/10.1080/0951192X.2014.880948.

[18] P. Karande and S. Chakraborty, "Material Handling Equipment Selection Using Weighted Utility Additive Theory," Journal of Industrial Engineering, vol. 2013, p. 268708, 2013. https://doi.org/10.1155/2013/268708.

[19] O. Kulak, "A decision support system for fuzzy multi-attribute selection of material handling equipments," Expert Systems with Applications, vol. 29, pp. 310-319, 2005. https://doi.org/10.1016/j.eswa.2005.04.004.

[20] A. D. Haidar and S. G. Naoum, "Opencast mine equipment selection using genetic algorithms," International Journal of Surface Mining, Reclamation and Environment, vol. 10, pp. 61-67, 1996. https://doi.org/10.1080/09208119608964801.

[21] Z. D. Unutmaz Durmuşoğlu, "Assessment of techno-entrepreneurship projects by using Analytical Hierarchy Process (AHP)," Technology in Society, vol. 54, pp. 4146, 2018. https://doi.org/10.1016/j.techsoc.2018.02.001.

[22] J. E. Leal, "AHP-express: A simplified version of the analytical hierarchy process $\begin{array}{lllll}\text { method," } \quad \text { MethodsX, } & \text { vol. } 7, \quad \text { p. } & 100748, & \end{array}$ https://doi.org/10.1016/j.mex.2019.11.021. 
[23] W. K. Brauers and E. K. Zavadskas, "The MOORA method and its application to privatization in a transition economy," Control and cybernetics, vol. 35, pp. 445469, 2006.

[24] P. P. Das, T. Y. Ladakhi, S. Sharma, and A. Patwardhan, "Supplier selection using multi-objective optimization based on ratio analysis," AIP Conference Proceedings, vol. 2273, p. 050018, 2020. https://doi.org/10.1063/5.0024464.

[25] P.-H. Nguyen, J.-F. Tsai, V. A. Kumar G, and Y.-C. Hu, "Stock investment of agriculture companies in the Vietnam stock exchange market: An AHP integrated with GRA-TOPSIS-MOORA approaches," The Journal of Asian Finance, Economics, and Business, vol. 7, pp. 113-121, 2020. https://doi.org/10.13106/jafeb.2020.vol7.no7.113.

[26] P. K. Patnaik, P. T. R. Swain, S. K. Mishra, A. Purohit, and S. Biswas, "Composite material selection for structural applications based on AHP-MOORA approach," Materials Today: Proceedings, vol. 33, pp. 5659-5663, 2020. https://doi.org/10.1016/j.matpr.2020.04.063.

[27] M. Chand, N. Bhatia, and R. K. Singh, "ANP-MOORA-based approach for the analysis of selected issues of green supply chain management," Benchmarking: An International Journal, vol. 25, pp. 642-659, 2018. https://doi.org/10.1108/BIJ-112016-0177.

[28] T. L. Saaty, "Decision making with the analytic hierarchy process," International Journal of Services Sciences, vol. 1, pp. 83-98, 2008. https://doi.org/10.1504/IJSSci.2008.01759.

[29] J. Browne, D. Dubois, K. Rathmill, S. P. Sethi, and K. E. Stecke, "Classification of flexible manufacturing systems," The FMS magazine, vol. 2, pp. 114-117, 1984.

[30] B. Bairagi, B. Dey, B. Sarkar, and S. K. Sanyal, "A De Novo multi-approaches multi-criteria decision making technique with an application in performance evaluation of material handling device," Computers \& Industrial Engineering, vol. 87, pp. 267-282, 2015. https://doi.org/10.1016/j.cie.2015.05.015.

[31] S. Kumar and R. Attri, "Prioritization of Variables Affecting the Effectiveness of Material Handling System," in IOP Conference Series: Materials Science and Engineering, 2020, p. 012031. https://doi.org/10.1088/1757-899x/804/1/012031.

[32] R. Ojstersek and B. Buchmeister, "The Impact of Manufacturing Flexibility and Multi-Criteria Optimization on the Sustainability of Manufacturing Systems," Symmetry, vol. 12, pp. 1-22, 2020. https://doi.org/10.3390/sym12010157.

[33] F. Ecer, "Multi-criteria decision making for green supplier selection using interval type-2 fuzzy AHP: a case study of a home appliance manufacturer," Operational Research, pp. 1-35, 2020. https://doi.org/10.1007/s12351-020-00552-y.

[34] J. Huiskonen, "Maintenance spare parts logistics: Special characteristics and strategic choices," International Journal of Production Economics, vol. 71, pp. 125133, 2001. https://doi.org/10.1016/S0925-5273(00)00112-2.

[35] P. Lorin, P. Khanna, P. Werle, and L. Eklund, "Transformer Condition Assessment: Methodologies and On-Site Repair Solutions," IEEE Industry Applications Magazine, vol. 20, pp. 50-57, 2014. https://doi.org/10.1109/MIAS.2013.2288382.

[36] A. Klausnitzer and R. Lasch, "Optimal facility layout and material handling network design," Computers \& Operations Research, vol. 103, pp. 237-251, 2019. https://doi.org/10.1016/j.cor.2018.11.002.

[37] J. Zurada, "Classifying the risk of work related low back disorders due to manual material handling tasks," Expert Systems with Applications, vol. 39, pp. 1112511134, 2012. https://doi.org/10.1016/j.eswa.2012.03.043. 
[38] B. Kumar, "Vacuum Gripper- An Important Material Handling Tool," International Journal of Science \& Technology, vol. 7, pp. 1-8, 2017.

[39] A. M. Momani and A. A. Ahmed, "Material handling equipment selection using hybrid Monte Carlo simulation and analytic hierarchy process," World Academy of Science, Engineering and Technology, vol. 59, pp. 953-958, 2011. https://doi.org/10.5281/zenodo.1085141.

[40] S. Kumar and T. Raj, "Selection of material handling equipment for flexible manufacturing system using FAHP," International Journal of Recent advances in Mechanical Engineering, vol. 5, pp. 25-45, 2016. 